\title{
Bedside assessment of respiratory viscoelastic properties in ventilated patients
}

\author{
V. Antonaglia*, A. Peratoner*, L. De Simoni*, A. Gullo*, J. Milic-Emili**, W.A. Zin ${ }^{+}$
}

\begin{abstract}
Bedside assessment of respiratory viscoelastic properties in ventilated patients. $V$. Antonaglia, A. Peratoner, L. De Simoni, A. Gullo, J. Milic-Emili, W.A. Zin. C) ERS Journals Ltd 2000

ABSTRACT: Viscoelasticity represents an important component of respiratory mechanics, being responsible, in some cases, for most of the pressure dissipated during breathing. Hitherto the methods available for determining the viscoelastic properties have been simplified, but are still time-demanding and depend on a great deal of calculation. In this study, a simple means of determining respiratory viscoelastic properties during mechanical ventilation was introduced.

The viscoelastic constants of the respiratory system, modelled as a Maxwell body, were studied in 17 normal subjects and seven patients with acute lung injury (ALI) using two end-inspiratory occlusions; one with a short inspiratory time (tI) to determine the elastic component of viscoelasticity and the other with a long $t$ to assess the resistive component of viscoelasticity.

The results were reproducible and similar to those provided by the previously described multiple-breath method $(\mathrm{MB})$. The mean $\pm \mathrm{SD}$ viscoelastic resistance was $5.31 \pm 1.50 \mathrm{~cm} \mathrm{H} \mathrm{H}_{2} \mathrm{O} \cdot \mathrm{L}^{-1} \cdot \mathrm{s}$ with the proposed method and $5.71 \pm 1.87 \mathrm{cmH}_{2} \mathrm{O} \cdot \mathrm{L}^{-1} \cdot \mathrm{s}$ with the $\mathrm{MB}$ method in normal subjects, and $8.93 \pm 2.82 \mathrm{cmH}_{2} \mathrm{O} \cdot \mathrm{L}^{-1} \cdot \mathrm{s}$ and $10.36 \pm 3.13$ $\mathrm{cmH}_{2} \mathrm{O} \cdot \mathrm{L}^{-1}$, respectively in ALI patients. The mean \pm SD viscoelastic elastance was $3.92 \pm$ $0.84 \mathrm{cmH}_{2} \mathrm{O} \cdot \mathrm{L}^{-1}$ and $4.94 \pm 1.01 \mathrm{cmH}_{2} \mathrm{O} \cdot \mathrm{L}^{-1}$ in normal subjects and $7.08 \pm 2.01 \mathrm{~cm} \mathrm{H}_{2} \mathrm{O} \cdot \mathrm{L}^{-1}$ and $8.21 \pm 1.16 \mathrm{~cm} \mathrm{H}_{2} \mathrm{O} \cdot \mathrm{L}^{-1}$ in ALI patients, respectively. The mean \pm sD viscoelastic time constant was $1.36 \pm 0.24 \mathrm{~s}$ and $1.17 \pm 0.34 \mathrm{~s}$ in normal subjects and $1.26 \pm 0.35 \mathrm{~s}$ and $1.24 \pm 0.23$ in ALI patients, respectively.
\end{abstract}

The method was easy to perform and applicable at the bedside in clinical routine. Eur Respir J 2000; 16: 302-308.

Viscoelasticity represents an important component of respiratory mechanics, being responsible, in some cases, for most of the pressure dissipated during breathing. In order to study the viscoelastic behaviour of the respiratory system, it is necessary to assess the pressure developed by the viscoelastic components. Direct measurement of the viscoelastic inspiratory pressure can be performed by the technique of rapid end-inspiratory airway occlusion and the viscoelastic behaviour interpreted according to a Maxwell body. This linear viscoelastic model has been shown to provide an accurate description of the time-dependency of resistance and elastance of the respiratory system observed in normal animal [1] and human lungs [2]

In this model, the viscoelastic properties which impact such time-dependency can be characterized by two parameters, the theoretical maximal viscoelastic resistance $(R 2)$ and elastance $(E 2)$. A third useful variable, the viscoelastic time constant $(\tau 2)$, can also be obtained from $R 2 / E 2$ [3]. Using the technique of rapid airway occlusion (RAO) during constant-flow $\left(V^{\prime}\right)$ inflation, it has been possible to determine the values of these viscoelastic constants for the lung, chest wall and total respiratory system in normal mechanically ventilated humans [3-5] and experimental animals $[1,6]$, based on either of the following functions:
*Dept of Anaesthesia and Intensive Care Laboratory of Respiratory Biomechanics, University of Trieste, Trieste, Italy; **Meakins-Christie Laboratories, Montreal Chest Institute Research Centre, McGill University, Montreal, Quebec, Canada; ${ }^{+}$Carlos Chagas Filho Biophysics Institute, Federal University of Rio de Janeiro, Rio de Janeiro, Brazil.

Correspondence: V. Antonaglia Ospedale di Cattinara Istituto Polidisciplinare di Anestesia, Rianimazione e Terapia Antalgica Strada di Fiume 447 I-34149 Trieste TS Italy Fax: 39040912278

Keywords: Acute lung injury

elasticity

mechanics

method

resistance

respiratory viscoelasticity

Received: May 201999

Accepted after revision April 262000

$$
\begin{gathered}
P_{\mathrm{visc}}(t)=R_{2} V^{\prime}\left(1-\mathrm{e}^{-t \mathrm{I} / \tau 2)}\right. \\
\Delta R_{\mathrm{rs}}(t)=P_{\mathrm{visc}}(t) / V^{\prime}=R_{2}\left(1-\mathrm{e}^{-t \mathrm{I} / \tau 2}\right)
\end{gathered}
$$

where $P$ visc $(t)$ is the viscoelastic pressure $\left(P_{\text {visc }}\right)$ dissipated within the lung, chest wall or both during constant$V^{\prime}$ inflation started from the relaxed volume of the respiratory system, $t$ is time during lung inflation and $\Delta R \mathrm{rs}$ is viscoelastic resistance, obtained by dividing both sides of Equation 1 by $V^{\prime}$ [3]. This analysis, however, is timeconsuming and technically complex because it requires either a series of isovolumic inflations with different inspiratory $V^{\prime}$, or multiple iso- $V^{\prime}$ inflations with different volumes [3, 6]. As a result, the above analysis has been used only in a limited number of studies on normal subjects [3-5] and patients [7-9].

Recently, a single-breath method was proposed for assessing the viscoelastic properties of the respiratory system, which was applied to normal subjects and acute lung injury (ALI) patients [10]. This method is based on the exponential analysis of the time course of tracheal pressure, $\left(P_{\text {tr }}\right)$, after RAO at baseline inflation volume. After occlusion, $P \operatorname{tr}$ shows an immediate fast fall from the peak value down to an inflection point $(P 1)$, followed by a 
slow decay to an apparent plateau, from which the elastic recoil pressure of the respiratory system $(P$ rs,st $)$ can be determined.

In the present investigation, a practical method for assessing the viscoelastic constants of the respiratory system, which can be performed without cumbersome exponential analysis is described. For such purpose, $P 1$ and $P$ rs,st are measured in only two different breaths, i.e. with short and prolonged inspiratory time $(t \mathrm{I})$. This method was used in normal anaesthetized paralysed subjects and in patients with ALI. The results were compared with those obtained on the same subjects using the multiple iso- $V^{\prime}$ inflations method.

\section{Theory}

As previously reported [10], after end-inspiratory airway occlusion, the difference between $P 1$ and $P$ rs,st reflects $P$ visc. At the time of occlusion, $t$, $P$ visc is maximal and can be denoted as $P_{\text {visc,max. }}$.

From Equation 1, $P_{\text {visc,max }}$ is given by:

$$
P_{\text {visc }, \max }=R 2 V^{\prime}\left(1-\mathrm{e}^{-t \mathrm{I} / \tau 2}\right)
$$

Dividing both sides of Equation 3 by tidal volume $(V \mathrm{~T})$, the value of the additional elastance of the respiratory system $(\Delta E \mathrm{rs})$ at $t$ I can be obtained [4]:

$$
\Delta E_{\mathrm{rs}}=P_{\mathrm{visc}, \max } / V_{\mathrm{T}}=R 2 \cdot V^{\prime}\left(1-\mathrm{e}^{-t \mathrm{I} / \tau 2}\right) / V_{\mathrm{T}}
$$

For very small $t$, the exponential term of Equation 4 can be considered equivalent to $1-t / \tau 2$ and $\Delta E$ rs can be approximated to $E 2$ [11]. Conversely, for large $t$ I the exponential term of Equation 2 becomes negligible and $\Delta R$ rs can be approximated to $R 2$. $\tau 2$ can then be obtained from $t 2=R 2 /$ E2.

Thus, using two single constant- $V^{\prime}$ inflations with one short and one long $t \mathrm{I}$ each followed by an end-inspiratory pause with occluded airway, the viscoelastic constants of the respiratory system can be obtained.

\section{Materials and methods}

Seventeen patients (12 male) undergoing general anaesthesia (premedication: diazepam, $7.5 \mathrm{mg}$ p.o.; anaesthesia: propofol, $2 \mathrm{mg} \cdot \mathrm{kg}^{-1}$ i.v.; muscle paralysis: succinylcholine, $1 \mathrm{mg} \cdot \mathrm{kg}^{-1}$ i.v.; maintenance: continuous infusion of propofol, $8-12 \mathrm{mg} \cdot \mathrm{kg}^{-1} \cdot \mathrm{h}^{-1}$, and vecuronium, $0.15 \mathrm{mg} \cdot \mathrm{kg}^{-1} \cdot \mathrm{h}^{-1}$ ) for minor lower abdominal or limb surgery were studied before skin incision. An inspiratory oxygen fraction $\left(F \mathrm{I}, \mathrm{O}_{2}\right)$ of 0.4 and no positive end-expiratory pressure (PEEP) were used. None had a history or clinical evidence of cardiopulmonary disease. Their mean \pm SD age, weight and height were $36 \pm 9 \mathrm{yrs}, 73 \pm 12 \mathrm{~kg}$ and $178 \pm 9 \mathrm{~cm}$, respectively. In all subjects, the vital capacity and forced expiratory volume at one second were within $\pm 10 \%$ of the predicted values [12].

Seven patients with ALI (arterial oxygen tension) $\mathrm{Pa}, \mathrm{O}_{2} /$ $F \mathrm{I}_{1} \mathrm{O}_{2}<300$ and bilateral infiltrates on chest radiography [13], who were admitted to the intensive care unit of Cattinara Hospital, were also studied. In all patients, the study was performed after haemodynamic stabilization for 1 day. The patients were sedated (propofol, $4 \mathrm{mg} \cdot \mathrm{kg}^{-1} \cdot \mathrm{h}^{-1}$ i.v.) and paralysed (vecuronium $0.15 \mathrm{mg} \cdot \mathrm{kg}^{-1} \cdot \mathrm{h}^{-\mathrm{P}} i . v$.).
Their anthropometric characteristics are shown in table 1. None had a history or clinical evidence of either restrictive or chronic lung disease, nor cardiogenic pulmonary oedema or active cardiac disease. The patients were studied at zero end-expiratory airway pressure. PEEP was removed $30 \mathrm{~min}$ before the study, and patients were judged to have reached a steady state by stability of respiratory mechanics and pulse oximetry records.

All subjects lay in the supine position, were intubated with a Rush cuffed endotracheal tube (inside diameter (ID) $7.5-8.0 \mathrm{~mm})$ and ventilated with constant inflation $V^{\prime}-$ controlled ventilation by means of a Servo Ventilator 900C (Siemens-Elema AB, Solna, Sweden). Rapid airway occlusions were performed using a solenoid valve (Airmatic $\mathrm{SV}$, Airmatic-Allied, Wilmington, OH, USA) placed next to the oral end of the endotracheal tube. The solenoid valve had a closing time of $11 \mathrm{~ms}$. The closing time was measured in the Electronics Laboratory, Dept of Energetics, Faculty of Engineering, Trieste, Italy, with an accelerometer (Brüel \& Kjær 4332; Brüel \& Kjær Italiana, Milan, Italy) and a current probe (AC-DC Fluke Y8100; Fluke Corporation, Everett, WA, USA) connected to a rapid recorder (Hioki 8830; Hioki E.E. Corporation, Nagano, Japan). $V^{\prime}$ was measured using a heated Jäger Baby pneumotachograph (Jäger, Würzburg, Germany) with a \pm 3 $\mathrm{L} \cdot \mathrm{s}^{-1}$ linearity range. The pneumotachograph was inserted between the end of the tracheal tube and the solenoid valve, and connected to a Validyne pressure transducer $( \pm 2$ $\mathrm{cmH}_{2} \mathrm{O}, \mathrm{MP}-45$, Validyne; Northridge, CA, USA) and to a carrier amplifier (13-4615-35, Gould, Inc.; Cleveland, OH, USA). Tracheal pressure was measured via a polyethylene catheter protruding $2-3 \mathrm{~cm}$ beyond the tracheal end of the endotracheal tube with a piezoresistive differential pressure transducer (Microswitch 142PC05D, Honeywell Ltd.; Scarborough, Ontario, Canada). The tracheal catheter (ID 1.5 $\mathrm{mm}$ ) had six side holes around its distal end and an occluded tip. The system used to measure $P$ tr showed no appreciable phase shift and the response was flat up to 20 $\mathrm{Hz}$. The overall dead space of the measuring equipment (excluding the endotracheal tube) was $35 \mathrm{~mL}$. The resistance offered by this equipment was $8 \mathrm{cmH}_{2} \mathrm{O} \cdot \mathrm{L}^{-1} \cdot \mathrm{s}$ at a $V^{\prime}$ of $1 \mathrm{~L} \cdot \mathrm{s}^{-1} . V^{\prime}$ and $P$ tr signals were fed through a 12-bit analogue-to-digital converter (Data Translation DT2801A, Data Translation, Inc.; Marlboro, MA, USA) into an IBMcompatible personal desk computer. The sampling frequency was established at $200 \mathrm{~Hz}$. Volume was obtained by numerical integration of the $V^{\prime}$ signal. All data were analysed using ANADAT data analysis software (RHT-InfoData, Inc., Montreal, Quebec, Canada).

Great care was taken to avoid leaks around the tracheal cuff and within the equipment. In all patients, the electrocardiogram and arterial blood pressure were continuously monitored as well as peripheral arterial oxygen saturation and end-tidal arterial carbon dioxide tension (Ohmeda 5250 RGM, Ohmeda, Louisville, CO, USA). An anaesthetist not involved in the experiment was continuously present to provide patient care.

\section{Experimental procedure and data analysis}

Normal subjects were ventilated as follows: $F \mathrm{I}, \mathrm{O}_{2}=0.4$, $V^{\prime}=0.53 \pm 0.02 \mathrm{~L} \cdot \mathrm{s}^{-1}$, tidal volume $(V \mathrm{~T})=7.5 \pm 0.8 \mathrm{~mL} \cdot \mathrm{kg}^{-1}$, 
Table 1. - Acute lung injury patient characteristics and diagnosis

\begin{tabular}{|c|c|c|c|c|c|c|}
\hline Patient No. & Sex & Height $\mathrm{cm}$ & Weight kg & Age yrs & Diagnosis & $P \mathrm{a}, \mathrm{O}_{2} / F \mathrm{I}, \mathrm{O}_{2} \mathrm{mmHg}$ \\
\hline 1 & M & 177 & 86 & 44 & Sepsis & 160 \\
\hline 2 & $\mathrm{~F}$ & 165 & 68 & 61 & Sepsis & 155 \\
\hline 3 & M & 173 & 75 & 67 & Multiple injury & 120 \\
\hline 4 & $\mathrm{~F}$ & 161 & 66 & 71 & Sepsis & 185 \\
\hline 5 & M & 176 & 71 & 73 & Sepsis & 190 \\
\hline 6 & M & 187 & 89 & 49 & Sepsis & 180 \\
\hline 7 & M & 168 & 73 & 43 & Sepsis & 160 \\
\hline
\end{tabular}

$\mathrm{Pa}_{\mathrm{a}} \mathrm{O}_{2}$ : arterial oxygen tension; $F \mathrm{I}, \mathrm{O}_{2}$ : inspiratory oxygen fraction; M: male; $\mathrm{F}$ : female. $(1 \mathrm{mmHg}=0.133 \mathrm{kPa}$.

inspiratory time $(t \mathrm{I})=0.99 \pm 0.09 \mathrm{~s}$, and respiratory frequency $(f \mathrm{R})=14-15$ breaths $\cdot \mathrm{min}^{-1}$. With these settings, there was normocapnia in all normal subjects and intrinsic PEEP (PEEPi) was absent, as indicated by each inflation being preceded by a period of zero $V^{\prime}$ (end-expiratory pause) and $P$ tr being zero during end-expiratory airway occlusions. The ALI group was ventilated as follows: $F_{1}, O_{2}=0.5, V^{\prime}=$ $0.52 \pm 0.09 \mathrm{~L} \cdot \mathrm{s}^{-1}, V \mathrm{~T}=6.3 \pm 0.7 \mathrm{~mL} \cdot \mathrm{kg}^{-1}, t \mathrm{I}=0.93 \pm 0.26 \mathrm{~s}, f \mathrm{R}$ of $16-18$ breaths $\cdot \mathrm{min}^{-1}$. The mean \pm SD PEEPi was $3.1 \pm 2.2$ $\mathrm{cmH}_{2} \mathrm{O}$.

Data collection started during an end-expiratory occlusion for assessment of PEEPi. The end-expiratory occlusion was followed by five recovery breaths at baseline ventilatory settings, followed by an end-inspiratory occlusion. All measurements were repeated three times under the same experimental conditions. Between each test, $V^{\prime}, V$ T, and $P$ tr were allowed to return to baseline levels.

End-tidal inspiratory occlusions, which lasted for $5 \mathrm{~s}$, were achieved using the solenoid valve triggered by the Servo Ventilator. The $V$ loss due to the continuous gas exchange had a negligible impact on $P$ tr. After the occlusion, an initial rapid drop in $P$ tr to $P 1$ (maximum pressure $(P \max ))$ pressure after first drop $(P 1))$ was followed by a subsequent gradual decrease to an apparent plateau pressure $(P$ rs,st $) . P$ tr measured $5 \mathrm{~s}$ after the onset of occlusion, was taken as the end-inspiratory $P$ rs,st. By dividing maximum $P \operatorname{tr}\left(P_{\text {tr,max }} P\right.$ rs,st and $P$ tr,max $\left.P 1\right)$ by the $V^{\prime}$ immediately preceding the occlusion, the total resistance of the respiratory system $(R \mathrm{rs})$ and the ohmic resistance of the respiratory system $(R \mathrm{rs}$,int) were obtained. $\Delta R$ rs was calculated as the difference bet-ween $R \mathrm{rs}$ and $R \mathrm{rs}$,int $[14,15]$. In computing $R$ rs,int the errors caused by the closing time of the valve, although minute, were corrected as previously described [16]. In this analysis, the onset of the occluded inspiration corresponded to the end of the preceding constant $V^{r}$ inflation obtained with a given $t I$. Accordingly, the difference $P 1-P$ rs, st should correspond to the $P$ visc at $t \mathrm{I}\left(P_{\mathrm{visc}}, \mathrm{max}\right)$. The static elastance of the respiratory system (Ers,st) was computed by dividing the corresponding $\times$ static PEEPi $(P$ rs,st PEEPist $)$ by $V$ T. The dynamic elastance of the respiratory system ( $E$ rs,dyn) was computed by dividing the corresponding $P 1$ PEEPist) by $V$ T.

\section{Short-and-long-breath method}

In each patient, $E 2$ was approximated to by $\Delta E$ rs obtained from inflations with small $t$ I and identical $V$. Conversely, $R 2$ was approximated to by $\Delta R$ rs obtained during inspirations with large $t$ I. From the ratio between $P 1-P$ rs,st and $V \mathrm{~T}$ pertaining to the corresponding short constant- $V^{r}$ lung inflation, $\Delta E$ rs was computed.
The mean values from three pairs of short-and-long breaths were used to measure $R 2, E 2$, and $\tau 2$.

\section{Multiple-breath method}

The iso- $V^{\prime}$ occlusion multiple breath (MB) method previously described in detail was used $[2,4]$. Under the same baseline conditions, 5-s end-inspiratory occlusions were performed at four or five different inflation $V$ by intermittently changing $t$ I while keeping the basal inflation $V^{\prime}$ constant. The corresponding occluded inflation $V$, ranged $0.19-1.55 \mathrm{~L}$. These tests were repeated three times. At each occlusion $V, \Delta R$ rs was obtained and, together with the corresponding $V^{\prime}$ and $t$, fitted to Equation 2 to obtain $R 2$ and $\tau 2$.

The investigation was approved by the local Ethics Committee, and informed consent was obtained from each individual or their next of kin.

\section{Statistical analysis}

Regression analysis was performed using the leastsquares method. The paired t-test was used to compare the data from the first test with the corresponding mean values obtained from the three repeat tests. Comparison of the results provided by the short- and long-breath and $\mathrm{MB}$ methods was performed by means of the limit of agreement [17], as modified for small sample sizes [18]. Correlations of the ratios $\Delta E \mathrm{rs} / E 2$ and $\Delta R \mathrm{rs} / R 2$ with $t \mathrm{I} / \tau 2$ were evaluated using the Pearson test. The significance level was established at $\mathrm{p}<0.05$.

\section{Results}

Table 2 depicts the mean \pm SD of $R$ rs,int, $\Delta R$ rs $E$ rs,st, and $E$ rs,dyn in normal subjects and ALI patients under baseline ventilatory settings obtained from three end-inspiratory occlusion tests.

Table 3 depicts the mean $\tau 2, R 2$, and $E 2$ obtained from three short and long tI breaths in normal subjects and ALI patients. The mean \pm SD intrasubject coefficients of variation of $\tau 2, R 2$, and $E 2$ were $8 \pm 4 \%, 5 \pm 3 \%$, and $7 \pm 2 \%$, respectively, in normal subjects, and $11 \pm 5 \%, 6 \pm 3 \%$, and $10 \pm 3 \%$ respectively, in ALI patients. Table 3 also depicts the mean \pm SD of $\tau 2, R 2$, and $E 2$ obtained with the MB test [1] in normal subjects and ALI patients. The mean \pm SD differences between the results of the short-and-longbreath and MB methods in normal subjects were: $\tau 2$, $0.17 \pm 0.26 \mathrm{~s} ; R 2,0.43 \pm 0.77 \mathrm{cmH}_{2} \mathrm{O} \cdot \mathrm{L}^{-1} \cdot \mathrm{s} ;$ and, $E 2,1 \pm 0.57$ 
Table 2. - Respiratory mechanical variables of 17 normal subjects and 7 acute lung injury (ALI) patients obtained at baseline tidal volume

\begin{tabular}{|c|c|c|c|c|c|c|c|c|}
\hline & \multicolumn{4}{|c|}{ Normal subjects } & \multicolumn{4}{|c|}{ ALI patients } \\
\hline & $\begin{array}{c}E \mathrm{rs}, \mathrm{st} \\
\mathrm{cmH}_{2} \mathrm{O} \cdot \mathrm{L}^{-1}\end{array}$ & $\begin{array}{c}\text { Ers,dyn } \\
\mathrm{cmH}_{2} \mathrm{O} \cdot \mathrm{L}^{-1}\end{array}$ & $\begin{array}{c}R \mathrm{rs}, \text { int } \\
\mathrm{cmHH}_{2} \mathrm{O} \cdot \mathrm{L}^{-1} \cdot \mathrm{s}\end{array}$ & $\begin{array}{c}\Delta R \mathrm{rs} \\
\mathrm{cmH}_{2} \mathrm{O} \cdot \mathrm{L}^{-1} \cdot \mathrm{s}\end{array}$ & $\begin{array}{c}E \text { rs,st } \\
\mathrm{cmH}_{2} \mathrm{O} \cdot \mathrm{L}^{-1}\end{array}$ & $\begin{array}{c}\text { Ers,dyn } \\
\mathrm{cmH}_{2} \mathrm{O} \cdot \mathrm{L}^{-1}\end{array}$ & $\begin{array}{c}R \mathrm{rs}, \text { int } \\
\mathrm{cmH}_{2} \mathrm{O} \cdot \mathrm{L}^{-1} \cdot \mathrm{s}\end{array}$ & $\begin{array}{c}\Delta R \mathrm{rs} \\
\mathrm{cmH}_{2} \mathrm{O} \cdot \mathrm{L}^{-1} \cdot \mathrm{s}\end{array}$ \\
\hline Mean & 18.1 & 21.2 & 1.71 & 3.11 & 21.9 & 31.7 & 4.21 & 4.9 \\
\hline SD & 4.8 & 4.5 & 0.91 & 0.75 & 7.1 & 12.2 & 1.61 & 1.25 \\
\hline
\end{tabular}

Data are the mean of three tests. Ers,st : static elastance of the respiratory system; Ers,dyn: dynamic elastance of the respiratory system; $R \mathrm{rs}$,int: ohmic resistance of the respiratory system; $\Delta R \mathrm{rs}$ : viscoelastic resistance of the respiratory system.

$\mathrm{cmH}_{2} \mathrm{O} \cdot \mathrm{L}^{-1}$. The mean \pm SD differences between $\tau 2, R 2$, and $E 2$ given by the short-and-long-breath and $\mathrm{MB}$ methods in ALI patients were: $-0.01 \pm 0.13 \mathrm{~s}, 1.24 \pm 0.68 \mathrm{cmH}_{2} \mathrm{O} \cdot \mathrm{L}^{-1} \cdot \mathrm{s}$ and $1.06 \pm 0.47 \mathrm{cmH}_{2} \mathrm{O} \cdot \mathrm{L}^{-1}$, respectively. No lack of agreement could be detected between the two methods for all variables in normal subjects and ALI patients.

The mean \pm SD short-breath $V \mathrm{~T}$ and $t$ i pertaining to occlusions of the present method were, in normal subjects, $0.345 \pm 0.04 \mathrm{~L}$ and $0.65 \pm 0.08 \mathrm{~s}$ and, in ALI patients, $0.358 \pm$ $0.06 \mathrm{~L}$ and $0.68 \pm 0.14 \mathrm{~s}$, respectively. The mean \pm SD ratio of short-breath $t \mathrm{I}$ and $\tau 2, t \mathrm{I}(\Delta E \mathrm{rs}) / \tau 2$, was $0.60 \pm 0.19$ in normal subjects, and $0.56 \pm 0.13$ in ALI patients. Figure 1 depicts the discrepancy between the $\Delta E$ rs obtained with the shortand-long-breath and $\mathrm{MB}$ methods $\left(\Delta E \mathrm{rs} / E_{2}\right)$ as a function of the discrepancy between the $t$ I pertaining to $\Delta E$ rs computation and the corresponding viscoelastic time constant, $t \mathrm{I}\left(\Delta E_{\mathrm{rs}}\right) / \tau 2$, for normal subjects and ALI patients. There was a significant inverse relationship between these two parameters for normal subjects $(\mathrm{y}=1.08-0.464 \mathrm{x}, \mathrm{r}=-0.851$, $\mathrm{p}<0.0001)$. The overall regression data for both normal subjects and ALI patients $(\mathrm{y}=1.09-0.458 \mathrm{x}, \mathrm{r}=-0.809$, $\mathrm{p}<0.0001$ ), are very similar to those gathered from normal subjects alone.

The mean \pm SD long-breath $V \mathrm{~T}$ and $t \mathrm{I}$ were, in normal subjects, $1.146 \pm 0.18 \mathrm{~L}$ and $2.22 \pm 0.36 \mathrm{~s}$ and, in ALI patients, $1.124 \pm 0.33 \mathrm{~L}$ and $2.11 \pm 0.49 \mathrm{~s}$, respectively. The mean $\pm \mathrm{SD}$ ratio $t \mathrm{I}(\Delta R \mathrm{rs}) / \tau 2$ was $2.07 \pm 0.72$ in normal subjects, and $1.71 \pm 0.39$ in ALI patients. The relationship between $t \mathrm{I}(\Delta R \mathrm{rs}) / \tau 2$ and the ratio $\Delta R \mathrm{rs} / R 2$ for normal subjects is illustrated in fig. 2. There was a significant relationship between these two parameters for normal subjects: $(y=0.637 \pm$ $0.148 \mathrm{x}, \mathrm{r}=-0.768, \mathrm{p}<0.0003)$. The overall regression data for both normal subjects and ALI patients $(y=0.628 \pm$ $0.151 \mathrm{x}, \mathrm{r}=0.779, \mathrm{p}<0.0001)$, are very similar to those obtained from normal subjects alone.

The viscoelastic constants were also obtained from the baseline end-inspiratory occlusion manoeuvre using the single-breath (SB) method [10]. The mean \pm SD differences between the results of the short-and-long-breath and SB methods in normal subjects were: $\tau 2,0.14 \pm 0.20 \mathrm{~s} ; R 2$, $0.11 \pm 0.68 \mathrm{cmH}_{2} \mathrm{O} \cdot \mathrm{L}^{-1} \cdot \mathrm{s}$; and $E 2,-0.55 \pm 0.88 \mathrm{cmH}_{2} \mathrm{O} \cdot \mathrm{L}^{-1}$. The mean \pm SD differences between $\tau 2, R 2$, and $E 2$ given by the short-and-long-breath and SB methods in ALI patients were: $0.06 \pm 0.36 \mathrm{~s},-0.37 \pm 1.37 \mathrm{cmH}_{2} \mathrm{O} \cdot \mathrm{L}^{-1} \cdot \mathrm{s}$, and $-0.28 \pm 1.76 \mathrm{cmH} \mathrm{H}_{2} \mathrm{O} \cdot \mathrm{L}^{-1}$, respectively. No lack of agreement could be detected between the two methods for all variables in normal subjects and ALI patients.

\section{Discussion}

As in previous studies [1, 4, 5, 10, 14], standard mechanical variables were obtained after end-inspiratory occlusions performed at baseline ventilation in the present study. The values of $E_{\mathrm{rs}, \mathrm{st}}, E_{\mathrm{rs}}$,dyn, $R \mathrm{rs}$,int, and $\Delta R \mathrm{rs}$ obtained in normal subjects are within the range reported in the literature $[1,4,5,10,14]$. The values obtained in ALI patients reflect marked inter-individual variation in respiratory mechanics (table 2).

Study of the viscoelastic behaviour of the respiratory system implies assessment of the pressure developed by the viscoelastic components. RAO permits the direct measurement of viscoelastic pressure and the present investigation shows that, from constant- $V^{\prime}$ lung inflation manoeuvres performed at short and prolonged periods of time, the viscoelastic constants of the respiratory system can be derived.

The results provided by the short-and-long breath and MB methods were in agreement. The mean differences between the two methods were nonsignificant, but E2 determined by the MB method in normal subjects and ALI patients were $\sim 1 \mathrm{cmH}_{2} \mathrm{O} \cdot \mathrm{L}^{-1}$ higher than those measured by the short-and-long-breath method. However, for the short $t \mathrm{I}$ inflations, the normal subjects were partitioned into two subpopulations, using as a cut-off the mean $\tau 2 / 2$, namely, $0.58 \mathrm{~s}$. When $t \mathrm{t}<0.58 \mathrm{~s}$ and $>0.58 \mathrm{~s}$, the mean \pm SD differences in $E 2$ between short-and-long-breath and $\mathrm{MB}$ methods were, respectively: $0.53 \pm 0.26 \mathrm{cmH}_{2} \mathrm{O} \cdot \mathrm{L}^{-1}$ and $1.33 \pm$ $0.49 \mathrm{cmH}_{2} \mathrm{O} \cdot \mathrm{L}^{-1}$. In other words, when using shorter inspirations (adequate for the determination of $E_{2}$ ) the difference

Table 3. - Viscoelastic time constant $(\tau 2)$, resistance $\left(R_{2}\right)$, and elastance $\left(E_{2}\right)$ of the respiratory system in 17 normal subjects and 7 acute lung injury (ALI) patients

\begin{tabular}{|c|c|c|c|c|c|c|}
\hline \multirow[b]{2}{*}{ Method } & \multicolumn{3}{|c|}{ Normal subjects } & \multicolumn{3}{|c|}{ ALI patients } \\
\hline & $\tau 2 \mathrm{~s}$ & $R 2 \mathrm{cmH}_{2} \mathrm{O} \cdot \mathrm{L}^{-1} \cdot \mathrm{s}$ & $E 2 \mathrm{cmH}_{2} \mathrm{O} \cdot \mathrm{L}^{-1}$ & $\tau 2 \mathrm{~s}$ & $R 2 \mathrm{cmH}_{2} \mathrm{O} \cdot \mathrm{L}^{-1} \cdot \mathrm{s}$ & $E_{2} \mathrm{cmH}_{2} \mathrm{O} \cdot \mathrm{L}^{-1}$ \\
\hline SLB & $1.36 \pm 0.24$ & $5.31 \pm 1.50$ & $3.92 \pm 0.84$ & $1.26 \pm 0.35$ & $8.93 \pm 2.82$ & $7.08 \pm 2.01$ \\
\hline MB & $1.17 \pm 0.34$ & $5.71 \pm 1.87$ & $4.94 \pm 1.01$ & $1.24 \pm 0.23$ & $10.36 \pm 3.13$ & $8.21 \pm 1.16$ \\
\hline
\end{tabular}

Data are presented as mean \pm SD. SLB: short-and-long-breath (mean of three tests); MB: multiple-breath. 


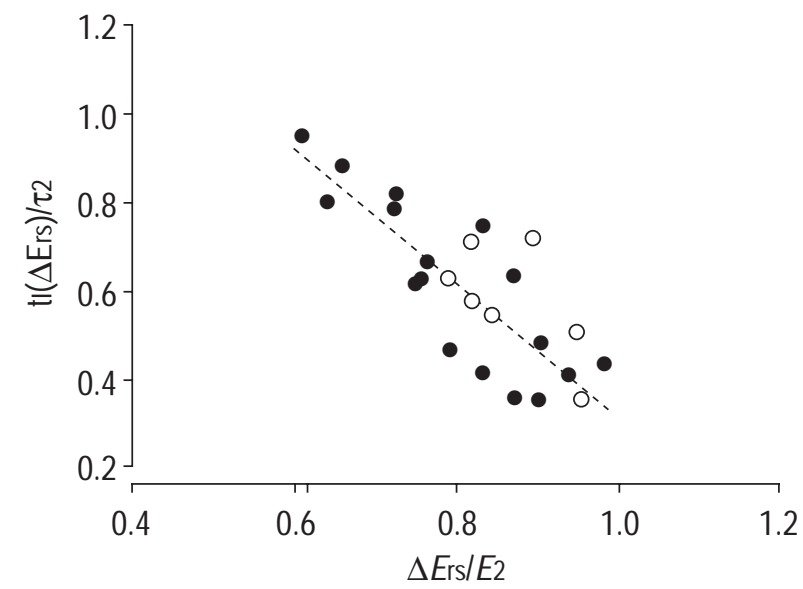

Fig. 1. - Relationship between $\operatorname{tI}(\Delta E \mathrm{rs}) / \tau_{2}$ and $\Delta E_{\mathrm{rs}} / E_{2}$ in the shortbreath lung inflation occlusion test in normal subjects $(\boldsymbol{O})$ and acute lung injury patients $(O)$, where $t \mathrm{I}(\Delta E \mathrm{rs})$ inspiratory time pertaining to the lung inflation occlusion test, $\tau 2$ the viscoelastic time constant, $\Delta E_{\mathrm{rs}}$ the viscoelastic elastance of the respiratory system and $E 2$ viscoelastic elastance. - - - - regression line for normal subjects $(\mathrm{r}=-0.851, \mathrm{p}<0.0001)$.

gets smaller (on average from 20 to $10 \%$ ). Figure 1 demonstrates that the shorter the $t \mathrm{I}$ in relation to $\tau 2$, the better $\Delta E$ rs represents $E 2$. In the same line, figure 2 shows that the longer the $t \mathrm{I}$ in relation to $\tau 2$, the better $\Delta R$ rs represents $R 2$.

As in normal subjects, in ALI patients, the viscoelastic constants could be obtained by the short-and-long-breath method, and the mean differences in $R 2$ and $E_{2}$ between the short-and-long-breath and MB methods were not zero, showing a systematic bias between the methods, although the agreement between the results was statistically confirmed [17, 18]. In ALI patients, the difference in $R 2$ between the two methods was, on average, $13.8 \%$. One patient showed a difference of $25 \%$ (see fig. 2). If this patient is not taken into account, the patients showed a mean difference of $10 \%$. Indeed, figures 1 and 2 show that the results for patients and normal subjects overlap. The systematic differences in $R 2$ and $E 2$ (on average of $10 \%$ ) in normal subjects and ALI patients are probably related to different computation of the viscoelastic constants, by direct measurements of parameters pertaining to the short-and-long-breath method in the present study and by exponential analysis of measurements of parameters pertaining to different inflation volumes. Thus, using the short-and-long-breath method, a small sacrifice in accuracy allows the easy determination of viscoelastic constants at the bedside.

Recently, an SB method for obtaining viscoelastic constants from a baseline end-inspiratory occlusion manoeuvre was presented [10]. Although better agreement was found between the results of the SB and MB methods [10] with respect to those of the present study, the viscoelastic constants obtained in the present investigation were not significantly different from those obtained using the SB method in the present subjects. The SB method requires exponential analysis of the time course of $P \operatorname{tr}$ after baseline end-inspiratory occlusion in order to obtain $P$ visc,max and $\tau 2$ and computation of $R 2$ from Equation 3, using $P_{\text {visc,max }}$ and $\tau 2$, together with the $V^{r}$ and $t$ I per-taining to the corresponding constant- $V^{\prime}$ lung

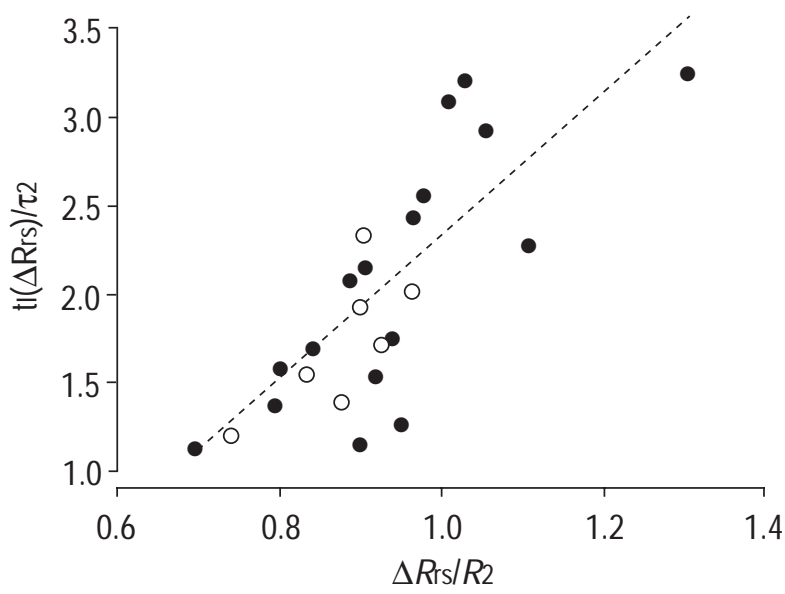

Fig. 2. - Relationship between $t \mathrm{I}(\Delta R \mathrm{rs}) / \tau 2$ and $\Delta R \mathrm{rs} / R 2$ in the shortbreath lung inflation occlusion test in normal subjects $(\mathbf{O})$ and acute lung injury patients $(O), t \mathrm{I}(\Delta E \mathrm{rs})$ where inspiratory time pertaining to the respiratory system, $\tau 2$ viscoelastic time constant, $\Delta R \mathrm{rs}$ the viscoelastic elastance of the respiratory system and $R 2$ viscoelastic resistance. - - - regression line for normal subjects $(r=-0.768, p<0.0003)$.

inflation. The present variant of the method requires only measure-ment of $P 1$ and $P$ rs,st and $V$ T at short $t$ inflation and $P 1, P$ rs,st and $V^{\prime}$ at long $t$ I inflation.

Figure 3 depicts the relationships of the mean E2 and $R 2$ to $t \mathrm{I} / \tau 2$ obtained with the present method in the 17 normal subjects and in seven ALI patients, together with those predicted according to Equations 2 and 4, using the mean values of the viscoelastic constants obtained with the MB method. In order to obtain an $R 2$ as close as possible to the predicted value, a $t$ determining a high ratio between $t \mathrm{I}$ and $\tau 2$ should be chosen. As can be seen, at $t \mathrm{I}(\Delta R \mathrm{rs}) / \tau 2>2$ the values of $R 2$ obtained with the present method are similar to the corresponding predicted values. Conversely, the linearity of the system can be compromised using a very prolonged inflation. In figure 2 , the

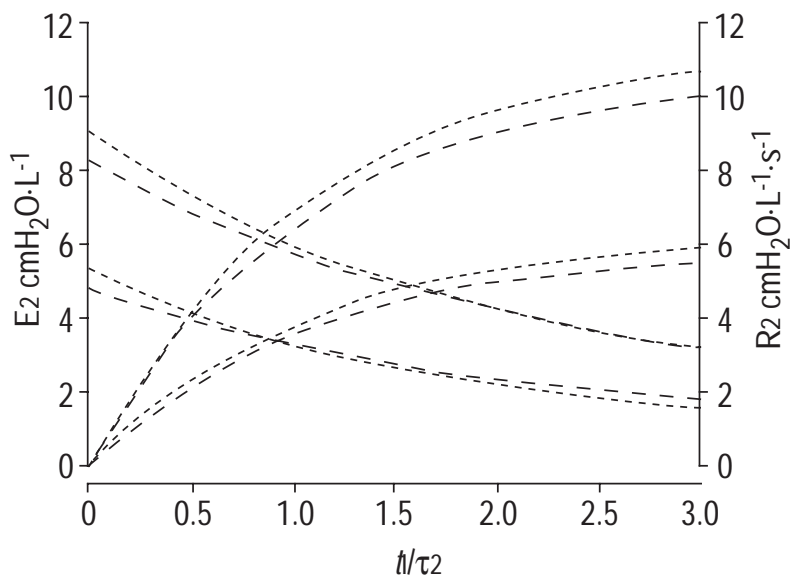

Fig. 3. - Relationship of the mean viscoelastic elastance (E2) and viscoelastic resistance $(R 2)$ to the ratio inspiratory time $(t \mathrm{I}) /$ viscoelastic time constant $(\tau 2)$ in normal subjects and acute lung injury (ALI) patients obtained with the short-and-long-breath method (- - - : normal subjects; - - - -: ALI patients) together with those predicted according to Equations 2 and 4, using the mean viscoelastic constants obtained with the multiple-breath method (- - -: normal subjects; - - - -: ALI patients). 
subject with $t \mathrm{I}(\Delta R \mathrm{rs}) / \tau 2>3$ and $\Delta R \mathrm{rs} / R 2>1.3$ may represent a case of loss of linearity. In the same figure, it can be observed that good agreement for $R 2(0.9<\Delta R \mathrm{rs} / R 2<1)$ can be obtained with a wide range of $t \mathrm{I} / \tau_{2}(1.2-2.6)$. At the extremity of this range, there were subjects with $\Delta R \mathrm{rs} /$ $R 2>1$ (possible expression of overdistension) and subjects and patients showing a significant difference between the two methods. Thus the mean value of the range (approximately $t \mathrm{I}=2 \tau 2$ ) should be a good approximation for choosing the value of prolonged $t$. In the present experimental conditions, it means a $t \mathrm{I}$ of $2.4 \mathrm{~s}$.

In order to obtain an $E 2$ as close as possible to the predicted value, the ratio $t \mathrm{t} / \tau 2$ should be very low. At $t \mathrm{I}<0.6 \mathrm{~s}$, a good agreement was obtained for E2. Because the mean $\tau 2$ are similar in normal subjects and ALI patients (1.2 s) $[1,6], t \mathrm{t}<0.6 \mathrm{~s}$ corresponds to $t \mathrm{I} / \tau 2<0.5$ in normal subjects and patients. Conversely, in relation to inflation $V^{\prime}, t$ must be long enough to obtain a $V$ T that inflates the lungs. At an inspiratory $V^{\prime}$ of $0.5 \mathrm{~L} \cdot \mathrm{s}^{-1}$, it is not possible to reduce $t \mathrm{I}$ below $0.3 \mathrm{~s}$. Also, under the present experimental conditions, a short $t \mathrm{I}$ is one of $0.3-0.6 \mathrm{~s}$.

In the present investigation, the effect of inhomogeneity has not been taken into consideration, which may affect measurements of viscoelastic properties. Even though inhomogeneity is expected to be greater in ALI patients, it did not jeopardize the results.

Using the iso- $V^{\prime}$ MB method and a modified MB method, D'ANGELo et al. [4] and Jonson et al. [19], respectively, determined the viscoelastic constants of the total respiratory system in normal subjects under similar experimental conditions to those of the present study. The values obtained were not significantly different to those presently reported.

The present analysis was based on the assumption that the respiratory system behaves as a linear viscoelastic model, which clearly should not be regarded as a complete and perfect representation of respiratory mechanics. More complex nonlinear viscoelastic [20] and viscoplastoelastic models [21] have been used to explain the volume and time dependency of energy dissipation within the respiratory system. Nevertheless, the linear viscoelastic model has been shown to provide an accurate description of the time dependency of resistance and elastance over the lung volume range used in the present study $[1,4,5]$. The present results show that the $t \mathrm{I}$-dependency of resistance and the elastance of the total respiratory system can be predicted with reasonable accuracy from the viscoelastic constants obtained using the present method.

The short-and-long-breath method is reproducible and requires only two occlusion tests compared to many repeated occlusion manoeuvres, as is the case for the iso- $V^{\prime}$ and iso- $V$ MB methods used previously $[1,4,5,10,14]$. In the present investigation, a rapid closure valve was used to close the airway. To ascertain the applicability of the proposed method in the clinical arena, the occluding valve of the ventilator was used to perform the end-inspiratory occlusion manoeuvre. Under the same experimental conditions, similar values of $\tau 2, R 2$ and $E 2$ were obtained in normal subjects and patients. As the short-and-long-breath method is applicable under the most common conditions in clinical routine and requires only measurement of $P 1, P$ rs,st, $V$ and $V$, avoiding complicated mathematical approaches, e.g. exponential analysis of the pressure curve or multiple end-inspiratory occlusions, it can be useful at the bedside, and may prove a powerful tool for the rapid evaluation of the effectiveness of therapeutic manoeuvres, e.g. sigh and removal of secretions by oscillatory ventilation.

\section{Conclusions}

The time-dependency of the resistance and elastance of the respiratory system can be explained using a linear viscoelastic model $[1,2]$. In order to evaluate this dependency, it is necessary to know the values of the parameters in this model $[2-4,7,9]$. The clinical utility of the present method lies in the possibility of performing only a few bedside measurements in order to obtain viscoelastic constants. This utility can justify the use of a simplified but perhaps less reliable method.

\section{References}

1. Mount LE. The ventilation flow-resistance and compliance of rat lungs. $J$ Physiol Lond 1955; 127: 157-167.

2. D'Angelo E, Calderini E, Torri G, Robatto FM, Bono D, Milic-Emili J. Respiratory mechanics in anesthetized paralyzed humans: effects of flow, volume, and time. $J$ Appl Physiol 1989; 67: 2556-2564.

3. Similovski T, Levy P, Corbeil C, et al. Viscoelastic behavior of lung and chest wall in dogs determined by flow interruption. J Appl Physiol 1989; 67: 2219-2229.

4. D'Angelo E, Robatto FM, Calderini E, et al. Pulmonary and chest wall mechanics in anesthetized paralyzed humans. J Appl Physiol 1991; 70: 2602-2610.

5. D'Angelo E, Calderini E, Tavola M, Bono D, Milic-Emili J. Effect of PEEP on respiratory mechanics in anesthetized paralyzed humans. J Appl Physiol 1992; 73: 17361742.

6. Shardonofsky FR, Skaburskis M, Sato J, Zin WA, MilicEmili J. Effects of volume history and vagotomy on pulmonary and chest wall mechanichs in cats. J Appl Physiol 1991; 71: 498-508.

7. Eissa NT, Ranieri VM, Corbeil C, et al. Analysis of behaviour of the respiratory system in ARDS patients: effects of flow, volume and time. J Appl Physiol 1991; 70: 2719-2729.

8. Eissa NT, Ranieri VM, Corbeil C, Chassé M, Braidy J, Milic-Emili J. Effect of PEEP on the mechanics of the respiratory system in ARDS patients. J Appl Physiol 1992; 73: 1728-1735.

9. Guerin C, Coussa ML, Eissa NT, et al. Lung and chest wall mechanics in mechanically ventilated COPD patients. J Appl Physiol 1993; 74: 1570-1580.

10. Antonaglia V, Grop A, Demanins P, et al. Single-breath method for assessing the viscoelastic properties of the respiratory system. Eur Respir $J$ 1998; 12: 1191-1196.

11. Lorino AM, Harf A. Techniques for measuring respiratory mechanics: an analytic approach with a viscoelastic model. J Appl Physiol 1993; 74: 2373-2379.

12. Morris JF, Koski A, Jonhson LC. Spirometric standards for hearty nonsmoking adults. Am Rev Respir Dis 1971; 103: 57-67.

13. Bernard GR, Artigas A, Brigham KL, et al. The American-European Consensus Conference of ARDS: definitions, mechanisms, relevant outcomes, and clinical 
trial coordination. Am J Respir Crit Care Med 1994; 149: 818-824.

14. Auler JOC Jr, Zin WA, Caldeira MPR, Cardoso WV, Saldiva PHN. Pre- and postoperative inspiratory mechanics in ischemic and valvular heart disease. Chest 1987 ; 92: 984-990.

15. D'Angelo E, Prandi E, Tavola M, Calderini E, Milic-Emili J. Chest wall interrupter resistance in anesthetized paralyzed humans. J Appl Physiol 1994; 77: 883-887.

16. Bates JHT, Hunter I, Sly P, Okubo S, Filiatrault S, MilicEmili J. The effect of valve closure time on the determination of respiratory resistance by flow interruption. Med Biol Eng Comp 1987; 25: 136-140.

17. Bland JM, Altman DG. Statistical methods for assessing agreement between two methods of clinical measurement. Lancet 1986; 1: 307-310.

18. Chinn S. Repeatability and method comparison. Thorax 1991; 46: 454-456.

19. Jonson B, Beydon L, Brauer K, Mansson C, Valind S, Grytzell H. Mechanics of respiratory system in healthy anesthetized humans with emphasis on viscoelastic properties. J Appl Physiol 1993; 75: 132-140.

20. Suki B, Bates JHT. A non linear viscoelastic model of lung tissue mechanics. J Appl Physiol 1991; 71: 826833 .

21. Hildebrandt J. Pressure-volume data of cat lung interpreted by a plastoelastic linear viscoelastic model. $J$ Appl Physiol 1970; 28: 365-372. 